\title{
A COMPARATIVE STUDY ON CANINE PARVOVIRUS INFECTION OF DOG IN BANGLADESH AND INDIA
}

\author{
M. M. Hasan ${ }^{1}$, M. S. Jalal ${ }^{1 *}$, M. Bayzid ${ }^{1}$, M. A. M. Sharif ${ }^{2}$ and M. Masuduzzaman ${ }^{3}$ \\ ${ }^{1}$ Department of Microbiology and Veterinary Public Health, ${ }^{2}$ Department of Animal Science and Nutrition, \\ ${ }^{3}$ Department of Pathology and Parasitology, Faculty of Veterinary Medicine, Chittagong Veterinary and Animal \\ Sciences University, Khulshi, Chittagong, Bangladesh
}

\begin{abstract}
A comparative study on Canine Parvovirus (CPV) infection among the hospitalized dogs at Central Veterinary Hospital $(\mathrm{CVH})$ in Bangladesh and Veterinary College and Research Institute-Madras Veterinary College (VCRI-MVC) in India was conducted during a period of January and July 2015. A total of 270 (80 at CVH and 190 at VCRI-MVC) hospitalized dogs of different breeds were clinically examined. The key clinical signs observed among the CPV infected dogs were bloody diarrhoea (90.4\%), vomition (94.5\%) and dehydration (severe $85.7 \%$, moderate $10.0 \%$ and mild $7.6 \%$ ). The overall prevalence of CPV infection was higher in VCRI-MVC (42.7\%) than CVH (31.2\%). The prevalence of CPV was varied significantly $(\mathrm{P}<0.05)$ among different age groups, vaccinated and non-vaccinated dogs. Highest prevalence was found $1-3$ months $(48.7 \%)$ old dogs, in compare with 4-6 months (17.2\%) and over 6 months $(8.3 \%)$ old dogs. Highest prevalence was also found in nonvaccinated than vaccinated dogs at $\mathrm{CVH}$, Bangladesh. In VCRI-MVC, India rate of infection also varied significantly $(\mathrm{P}<0.05)$ in different age groups $(57.4 \%, 28.9 \%, 10.0 \%$ among $1-3$ months, $4-6$ months and $>6$ months respectively) and $13.2 \%$ in vaccinated and $64.4 \%$ in non-vaccinated groups. Significant $(\mathrm{P}<0.05)$ variation in prevalence of CPV also observed in different breeds- indigenous (50.0\%), Spitz (28.2\%), Lhasa (18.1\%), Doberman (40.0\%) and German Shepherd (46.6\%).
\end{abstract}

Key words: CPV, CVH, VCRI-MVC, Prevalence.

\section{INTRODUCTION}

Canine parvovirus (CPV) infection is an infectious and contagious viral disease of canine especially dogs. Parvovirus comes from Latin word "Parvus" which means small and probably due to this reason this virus is known as parvovirus. It is a non-enveloped having a single stranded DNA genome belonging to the family Parvoviridae (Aappel et al., 1978) CPV is genetically and antigenically unrelated to Canine Minute Virus (CnMV), formerly known as canine parvovirus type 1 (CPV-1), which is responsible for neonatal death in dogs (Tattersall et al., 2005). Dogs of all age groups may be infected but puppies of 3 month of age are highly susceptible than adults (Behera et al., 2015). This virus causes high morbidity (100\%) and frequent mortality up to $10 \%$ in adult dogs and $91 \%$ in pups (Aappel et al., 1978). Canine parvovirus (CPV) emerged in the late 1970s, probably from feline panleukopenia virus via genetic mutations and evolution (Tattersall et al., 2005).

CPV infection is characterized by vomition, diarrhea and dehydration, brownish or bloody foul smelling diarrhoea and in severe cases fever (Pollock and Coyne, 1993). The clinical manifestations of CPV infection depends on the age and immune status of the dogs, virulence of the virus, dose of the virus and pre-existing or concurrent parasitic, bacterial or virus infections (McAdaragh et al., 1982) Factors that predispose parvovirus infection in puppies are lack of protective immunity, intestinal parasites, overcrowded, unsanitary, and stressful environmental conditions (Hoskins, 1997). It has been stated that Doberman, Rottweiler and German shepherd (GS) dogs seem to be more susceptible to Parvovirus infection than other breed (Ling et al., 2012) Unvaccinated puppies aged between six weeks and six months are at greatest risk of developing CPV related disease (Godsall et al., 2010)

The prevalence of canine parvovirus infection was reported as $77-80.4 \%$ in Thailand, $82.9 \%$ in Korea and $6 \%$ in Lithuania (Grigonis et al., 2002). The outbreak of CPV disease in dogs was also reported in Belgium and France (1977), Thailand, USA(1978), Portugal, Pakistan, Italy, Spain, Germany (Lamm and Rezabek, 2008). In India $1^{\text {st }}$ outbreak of CPV infection was reported in Madras (1981) and in Bombay (1985) (Haque and Arfa, 2012). Though diarrhea is one of common clinical features faced by the pet practitioners, but in Bangladesh, there is no published literature on canine parvovirus infection of dogs (Islam et al., 2014).

*Corresponding e-mail address: shah.jalal.baty@gmail.com

Copyright (c) 2016 Bangladesh Society for Veterinary Medicine

All rights reserved 0381/2016 


\section{M.M. Hasan and others}

\section{MATERIALS AND METHODS}

\section{Location, duration of study and study population}

The study was conducted at Central veterinary hospital $(\mathrm{CVH})$, Bangladesh and clinics of Veterinary College and Research Institute (VCRI) and clinics of Madras Veterinary College (MVC), India; during the period of January to march 2015. The hospitalized dogs were considered as study population. Total 270 (80 at CVH and 190 at VCRI-MVC) dogs of different breeds (Indigenous and Exotic breed i.e. Spitz, Lhasa, Doberman, and GS) were clinically examined during the study period. The data related to age, sex, breed, vaccination, clinical history etc were collect from owner using a standard case report sheet. Then rectal temperature, heart rate and respiration rate was measured. Skin fold test was performed to estimate the degree of dehydration. Diagnosis is based on clinical signs. For example, in enteritis forms, signs appear within 5 to 7 days after exposure including depression, loss of appetite, high fever (above $104^{\circ} \mathrm{F}$ ), vomition, bloody diarrhea are often seen, feces are generally light grey or yellow gray and may be streaked with blood and in myocarditis form which is usually seen in younger puppies less than 8 week of age. Dyspnea, Crying and retching finally death occur within 24 hours. Sometimes sudden death can occur without showing any cardinal signs due to Cardiac failure.

\section{Statistical Analysis}

All the data were included into microsoft office excel-2010. Then the data was cleaned, coded and finally analyzed using statistical software STATA version-13/C. Prevalence was calculated accordingly and expressed in percentage. To measure the association between categorical variables with the outcomes, chi-square test was performed with $95 \%$ level of confidence and 5\% level of significance.

\section{RESULTS AND DISCUSSION}

In $\mathrm{CVH}$ among the 80 clinically sick dogs, 25 were found positive for CPV infection. Prevalence of different risk factors (Age, Sex, Breed, Vaccination Status, Dehydration and Diarrhea) associated with CPV disease is summarized in Table 1.

Table 1. Prevalence of CPV Infection according to different risk factors at $\mathrm{CVH}$

\begin{tabular}{|c|c|c|c|c|c|}
\hline Variables & Category level & $\begin{array}{c}\text { No of observation } \\
(\mathrm{N}=80)\end{array}$ & Positive Case & $\begin{array}{c}\text { Prevalence } \\
(\%)\end{array}$ & P value \\
\hline \multirow{3}{*}{ Age } & $1-3$ month & 39 & 20 & 48.7 & \multirow{3}{*}{0.004} \\
\hline & Month & 29 & 5 & 17.2 & \\
\hline & $>6$ month & 12 & 1 & 8.3 & \\
\hline \multirow[b]{2}{*}{ Sex } & Male & 44 & 16 & 36.3 & \multirow[b]{2}{*}{0.275} \\
\hline & Female & 36 & 9 & 25.0 & \\
\hline \multirow{5}{*}{ Breed } & Indigenous & 10 & 3 & 30.0 & \multirow{5}{*}{0.079} \\
\hline & Spitz & 34 & 14 & 41.1 & \\
\hline & Lhasa & 14 & 2 & 22.2 & \\
\hline & Doberman & 14 & 3 & 21.4 & \\
\hline & GS & 8 & 3 & 37.5 & \\
\hline \multirow[t]{2}{*}{ Vaccination } & Yes & 45 & 4 & 8.8 & \multirow[b]{2}{*}{0.001} \\
\hline & No & 35 & 21 & 60.0 & \\
\hline
\end{tabular}

The study revealed that, the overall prevalence of CPV infection during the study period at $\mathrm{CVH}$ in Bangladesh was $31.2 \%$. The prevalence of $\mathrm{CPV}$ infection in different age group differed significantly $(\mathrm{P}<0.05)$ and these were $48.7 \%$ for $1-3$ months, $17.2 \%$ for $4-6$ months and $8.3 \%$ for above 6 months of ages. Between two different sexes the prevalence was insignificantly $(\mathrm{P}>0.05)$ higher in male $(36.3 \%)$ than female $(25.0 \%)$. 
A comparative study on canine parvovirus infection of dog

Table 2. Prevalence of CPV Infection according to different risk factors in VCRI-MVC.

\begin{tabular}{|c|c|c|c|c|c|}
\hline Variables & Category level & $\begin{array}{l}\text { No of Observation } \\
(\mathrm{N}=190)\end{array}$ & Positive case & Prevalence (\%) & $P$ value \\
\hline \multirow{3}{*}{ Age } & $1-3$ month & 101 & 58 & 57.4 & \multirow{3}{*}{0.001} \\
\hline & 4-6 month & 69 & 20 & 28.9 & \\
\hline & $>6$ month & 20 & 2 & 10.0 & \\
\hline \multirow[t]{2}{*}{ Sex } & Male & 95 & 33 & 33.7 & \multirow[b]{2}{*}{0.040} \\
\hline & Female & 95 & 47 & 49.4 & \\
\hline \multirow{5}{*}{ Breed } & Indigenous & 84 & 42 & 50.0 & \multirow{5}{*}{0.001} \\
\hline & Spitz & 39 & 12 & 30.7 & \\
\hline & Lhasa & 22 & 5 & 22.7 & \\
\hline & Doberman & 30 & 12 & 40.0 & \\
\hline & GS & 15 & 9 & 46.6 & \\
\hline \multirow[t]{2}{*}{ Vaccination } & Yes & 83 & 11 & 13.2 & \multirow[b]{2}{*}{0.001} \\
\hline & No & 107 & 69 & 64.4 & \\
\hline
\end{tabular}

Among the breeds the rate of infections were encountered as 30.0\%in indigenous,41.1\% in Spitz,22.2\% in Lhasa, $21.4 \%$ in Doberman, $37.5 \%$ in GS in which were differed insignificantly $(\mathrm{P}>0.05)$. While considering vaccination status against $\mathrm{CPV}$ there observed a substantial difference $(\mathrm{P}<0.01)$ in occurrence of $\mathrm{CPV}$ infection which were $8.33 \%$ in vaccinated dogs and $60.0 \%$ in non-vaccinated dogs. At VCRI-MVC, in India-190dogs were studied, of which 80 were found positive. The risk factors (Age, Sex, Breed and Vaccination Status) which influence the prevalence of CPV infection are summarized in Table 2. The estimated prevalence of CPV disease at VCRI-MVC in India was 42.1\%.In compared with age wise distribution, prevalence was significant $(\mathrm{P}<0.05)$, it was $57.4 \%$ for $1-3$ months, $28.9 \%$ for $4-6$ months, and $10.0 \%$ for above 6 months. Between male and female prevalence was statistically significant $(\mathrm{P}<0.05)$ in where male $33.7 \%$, and female $49.4 \%$. Among the breeds of dog, prevalence were significant $(\mathrm{P}<0.05)$ in where $50.0 \%$ for Indigenous, $30.7 \%$ for Spitz, $28.2 \%$ for Lhasa, $40.0 \%$ for Doberman and $46.6 \%$ for GS. Moreover, Vaccinated 13.2\%and Non-vaccinated 64.4\% were significantly $(\mathrm{P}<0.05)$ affected with $\mathrm{CPV}$ infection. Table 3 represents the data of comparative study of CPV associated risk factors. It was revealed that the prevalence of different risk factors associated with CPV infections was insignificant $(\mathrm{P}>0.05)$ between $\mathrm{CVH}$ and VCRI-MVC.

Table 3. Comparison on prevalence of CPV Infection between CVH, Bangladesh and VCRI-MVC, India.

\begin{tabular}{ccccc}
\hline Variables & Category & Prevalence (\%)(Bangladesh) & Prevalence (\%) ( India ) & P value \\
\hline Age & $1-3$ month & 48.7 & 57.4 & 0.288 \\
& $4-6$ month & 17.2 & 28.3 & 0.188 \\
& $>6$ month & 8.3 & 10.0 & 0.756 \\
\hline \multirow{2}{*}{ Sex } & Male & 36.3 & 33.7 & 0.149 \\
& Female & 25.0 & 49.4 & 0.756 \\
\hline \multirow{2}{*}{ Breed } & Indigenous & 30.0 & 50.0 & 0.685 \\
& Spitz & 43.3 & 30.7 & 0.820 \\
& Lhasa & 22.2 & 22.7 & 0.897 \\
& Doberman & 21.4 & 40,0 & 0.999 \\
& GS & 37.5 & 46.6 & 0.472 \\
\hline Vaccination & Vaccinated & 8.8 & 13.2 & 0.464 \\
& Non-vaccinated & 60.0 & 64.4 & 0.633 \\
\hline
\end{tabular}


M.M. Hasan and others

Table 4. Different clinical signs observed among the CPV Infection in dogs.

\begin{tabular}{ccccc}
\hline Variables & Category & No of Observation $(\mathrm{N})$ & Positive case $(\mathrm{N})$ & $\%$ \\
\hline Bloody & Yes & 105 & 100 & 90.4 \\
Diarrhea & No & 165 & 5 & 3.0 \\
\hline Vomition & Yes & 110 & 104 & 94.5 \\
& No & 160 & 1 & .6 \\
\hline Dehydration & Severe & 105 & 90 & 85.7 \\
& Moderate & 100 & 10 & 10 \\
& Mild & 65 & 5 & 7.6 \\
\hline
\end{tabular}

Study revealed that in $90.4 \%$ bloody diarrhea, $94.5 \%$ vomition and $85.71 \%$ Severe, $10.0 \%$ moderate, $7.6 \%$ mild dehydration present in CPV infection (positive) in dogs.

The study revealed an overall prevalence of CPV infection in suspected dogs in CVH was $31.2 \%$. The result is an agreement with other reports that prevalence of canine parvovirus infection in street Dogs, at Mymensingh metropolitan City, in Bangladesh was 30.0\% (Islam et al., 2014).Overall prevalence of CPV infection in suspected dogs in VCRI-MVC, India was $42.1 \%$. Similar findings were reported previously where prevalence was $40.8 \%$ (Behera et al., 2015). Prevalence of CPV infection is higher in India than Bangladesh .This might be occur due to presence of endemic infection in the population under study at VCRI-MVC in India. Prevalence of CPV infection was higher among 1-3 month of age group than other age groups which support the study conducted by Vivek (2011). Again younger puppies ( $\leq 3$ months) is mostly affected which might be due to the affinity of the virus being multiplying rapidly at intestinal crypt cells at the weaning age along with higher mitotic index. Prevalence of CPV infection below 3 month of age puppies was insignificantly higher in VCRI, MVC than $\mathrm{CVH}$. Once again in $\mathrm{CVH}$, prevalence of $\mathrm{CPV}$ infection was slightly higher in male $(36.3 \%)$ compared with female (25.0\%). The study was in agreed with Islam et al. (2014). Oppositely female dogs were higher in susceptible (49.4\%) than the male (33.7\%) in VCRI-MVC, supported by finding of Umar et al. (2015). The susceptibility of Female was higher in CPV infection (India) however in Bangladesh male was higher in susceptible, it was due to most of the Indian people kept female for breeding purpose than Bangladeshi people. Breed wise distribution shown that prevalence of CPV disease was more in exotic breed than local indigenous in CVH. Among the exotic breeds Spitz, GS, Doberman were more susceptible. Among the breeds in VCRI-MVC, The occurrence of CPV infection is significantly higher in Local indigenous than the exotic breeds which is supported by research findings of Shukla et al. (2009). This study also exposed that among the exotic breeds GS, Doberman were higher in susceptibility than the others breed due to inherited immunodeficiency. It was supported by Singh et al. (2013), where CPV infection was highest in German shepherd (70\%), followed by Doberman (55\%). In CVH, Spitz was more susceptible due to its small size \& most preferable breed in Bangladeshi people. In MVC-VCRI Local indigenous dogs were higher susceptible due to higher population density of this breed, poor vaccination and lack of awareness. Among exotic breed GS, Doberman were highly susceptible. In non-vaccinated dogs the prevalence was higher in compared with vaccinated one. The finding was agreed with finding of Godsall et al. (2010) where unvaccinated puppies aged between six weeks and six months are at greatest risk of developing CPV infection. The higher prevalence of CPV infection in Non-vaccinated dogs in due to Lack of protective immunity. In vaccinated dogs there was also presence of CPV infection this might be occurred due to, incomplete or ineffective primary vaccination course, or failure of vaccination. The study was performed on the basis of tentative diagnosis by observing clinical signs and symptoms. The main clinical signs of CPV disease are Bloody diarrhea, Vomition, Dehydration. The study findings were an agreement with findings of Prittie (2004) and Thomson \& Gagnon (1987). In 90.4\% and 94.5\%CPV positive dogs, there were presence of bloody diarrhea and vomition (Table 5). Similar finding was also reported by Thomson and Gagnon (1978). About $85.7 \%$ CPV positive dogs were severe dehydrated that was reported in previous study, as an important sign of CPV infection (Laforcade et al., 2003).

In conclusion, canine Parvovirus is an infectious and highly contagious viral disease of dogs. Dogs of all age groups are infected but puppies age less than 3 month are highly susceptible than adults. Both male and female can be infected with CPV. Both indigenous and exotic breed(German shepherd, Doberman, Spitz, Lhasa), are susceptible to $\mathrm{CPV}$ infection. The rate of infection is high in non-vaccinated than vaccinated dogs. The prevalence of this disease is higher in India than Bangladesh. 


\section{REFERENCES}

1. Aappel M, Cooper B, Greisen H and Carmichael L (1978). Status-Report-Canine Viral-Enteritis. American Veterinary Medical Assoc 1931 N Meacham Rd Suite 100, Schaumburg, Il 60173-4360

2. Behera M, Panda SK, Sahoo PK, Acharya AP, Patra RC, Das S and Pati S (2015). Epidemiological study of canine parvovirus infection in and around Bhubaneswar, Odisha, India. Veterinary World 8: 33.

3. Godsall SA, Clegg SR, Stavisky JH, Radford AD, Pinchbeck G (2010). Epidemiology of canine parvovirus and coronavirus in dogs presented with severe diarrhoea to PDSA PetAid hospitals. Veterinary Record 167: 196-201.

4. Grigonis A, Macijauskas V and Zamokas G (2002). Examination of liver functions in dogs with parvovirus enteritis. Veterinarija-ir-Zootechnika 17: 23-8.

5. Haque S and Arfa T (2012). Epidemeological study of parvo gastroenteritis and its management by different concentrations of fluid in pups. Indian Journal of Canine Practice 4: 83

6. Hoskins JD (1997). Update on canine parvoviral enteritis. Veterinary Medicine (1985), USA.

7. Islam MR, Islam MA, Rahman MS, Uddin MJ, Sarker MA, Akter L and Alam E (2014). Prevalence of canine parvovirus infection in street dogs in Mymensingh Municipality area, Bangladesh. Microbes and Health 3: 5-6.

8. Laforcade AM, Freeman LM, Shaw SP, Brooks MB, Rozanski EA and Rush JE (2003). Hemostatic changes in dogs with naturally occurring sepsis. Journal of Veterinary Internal Medicine 17: 674-9.

9. Lamm CG and Rezabek GB (2008). Parvovirus infection in domestic companion animals. Veterinary Clinics of North America: Small Animal Practice 38: 837-50.

10. Ling M, Norris JM, Kelman M and Ward MP (2012). Risk factors for death from canine parvoviral-related disease in Australia. Veterinary Microbiology 158: 280-90.

11. McAdaragh JP, Eustis SL, Nelson DT, Stotz I and Kenefick K (1982). Experimental infection of conventional dogs with canine parvovirus. American Journal of Veterinary Research 43: 693-6.

12. Pollock RV and Coyne MJ (1993). Canine Parvovirus. Veterinary Clinics of North America: Small Animal Practice 23: 555-568.

13. Prittie J (2004). Canine parvoviral enteritis: a review of diagnosis, management, and prevention. Journal of Veterinary Emergency and Critical Care 14: 167-76.

14. Shukla P, Gupta D and Kumar B (2009). Epidemiology on canine parvovirus Infection. Indian Journal of Veterinary Research 18: 42-44.

15. Singh D, Verma AK, Kumar A, Srivastava MK, Singh SK, Tripathi AK, Srivastava A and Ahmed I (2013). Detection of canine parvovirus by polymerase chain reaction assay and its prevalence in dogs in and around Mathura, Uttar Pradesh, India. American Journal of Biochemistry and Molecular Biology 3: 264-70.

16. Tattersall P, Bergoin M, Bloom M, Brown K, Linden R, Muzyczka N, Parrish C and Tijssen P (2005). Family Parvoviridae. Virus Taxonomy: Eighth Report of The International Committee on Taxonomy of Viruses; 353-369.

17. Thomson GW and Gagnon AN (1978). Canine gastroenteritis associated with a parvovirus-like agent. The Canadian Veterinary Journal 19: 346.

18. Umar S, Ali A, Younus M, Maan MK, Ali S, Khan WA and Irfan M (2015). Prevalence of Canine Parvovirus Infection at Different Pet Clinics in Lahore, Pakistan. Pakistan Journal of Zoology 47: 657-63.

19. Vivek V (2011). Molecular Epidemiology of Canine Parvovirus in Southern India. Mvsc Thesis. Pondicherry University, Puducherry. 